\title{
Slow Resorption of Anorganic Bovine Bone by Osteoclasts in Maxillary Sinus Augmentation
}

\author{
Pablo Galindo-Moreno, DDS, PhD; ${ }^{\star}$ Pedro Hernández-Cortés, MD, PhD; ${ }^{\dagger}$ Francisco Mesa, MD, PhD; ${ }^{\ddagger}$ \\ Nelson Carranza, DDS, $\mathrm{PhD}{ }^{\S}$ Gintaras Juodzbalys, DDS, $\mathrm{PhD}{ }^{\Im}{ }^{\Im}$ Mariano Aguilar, $\mathrm{MD}, \mathrm{PhD} ;{ }^{* *}$ \\ Francisco O’Valle, MD, $\mathrm{PhD}^{* *}$
}

\begin{abstract}
Purpose: Different biomaterials have been suggested for guided bone regeneration (GBR). These might show the ideal properties to let a new bone formation in the grafted area. Among these ideal features, it is essential their controlled resorption in order to be replaced for new vital bone. Bovine bone has been used widely as a good biomaterial for GBR, however there is still an interesting controversy about its resorbable capacity. In this sense, the objective of this study was to examine the behavior of anorganic bovine bone (ABB) in long-term maxillary sinus graft healing and study its relationship with morphological and morphometrical variables.
\end{abstract}

Materials and Methods: Seventeen maxillary sinus augmentation procedures were performed in patients. Bone cores were obtained from implant receptor sites at 6 months, 3 years, and 7 years of implant placement for histological, morphometric, and immunohistochemical (tartrate resistant acid phosphatase [TRAP]/cathepsin K/CD68) studies.

Results: The percentages of bone, ABB particles, connective tissue, osteocytes, and osteoblasts in maxillary sinus grafts were similar at 6 months, 3 years, and 7 years. A progressive and significant decrease was detected in osteoclasts $(p=.05$, Kruskal-Wallis test), TRAP and cathepsin K expression ( $p=.014$ and $p=.021$, respectively), and osteoid lines $(p=.038)$.

Conclusion: According to these data, a decrease in osteoclasts over time may, partially, explain the ABB persistence observed in core biopsies. Further studies with more cases and different graft maturation times are required to elucidate the resorption rates and cell events underlying these phenomena.

KEY WORDS: anorganic bovine bone, bone remodeling, cathepsin $\mathrm{K}$, immunohistochemistry, intrasinus graft, osteoclasts, osteocyte, resorption, TRAP

\section{INTRODUCTION}

Multiple types of bone graft material (autogenic, allogenic, xenogeneic, and alloplastic) have been used for

\footnotetext{
*Associate professor, Oral Surgery and Implant Dentistry Department, School of Dentistry, University of Granada, Granada, Spain; visiting associate professor, Department of Periodontics and Oral Medicine School of Dentistry, University of Michigan, Ann Arbor, MI, USA; ${ }^{\dagger}$ associate professor, Traumatology and Orthopedic Surgery Department, "San Cecilio" Clinical Hospital and University of Granada, Granada, Spain; "associate professor, Periodontology Department, School of Dentistry, University of Granada, Granada, Spain; ${ }^{\$}$ professor and chairman, Periodontology Department, School of Dentistry, University of Buenos Aires, Buenos Aires, Argentina; 'professor, Department of Maxillofacial Surgery, Lithuanian University of Health Sciences, Kaunas, Lithuania; ${ }^{*}$ associate professor, Pathology Department, School of Medicine, and IBIMER, University of Granada, Granada, Spain
}

Reprint requests: Dr. Pablo Galindo-Moreno, DDS, PhD, C/ Recogidas, $395^{\circ}$ Izq, 18005 Granada, Spain; e-mail: pgalindo@ugr.es

(C) 2012 Wiley Periodicals, Inc.

DOI 10.1111/j.1708-8208.2012.00445.x bone defect repair and sinus augmentation to provide structural and mechanical support for the placement of dental implants. ${ }^{1}$ Successful graft consolidation relies on the progressive apposition of newly formed vital bone, followed by functional remodeling and progressive replacement of the grafting material by vital tissue. ${ }^{2}$ Therefore, according to the ideal criteria for a biomaterial, bone substitute biomaterials should be osteogenic, osteoconductive, and/or osteoinductive, ${ }^{3}$ promote angiogenesis, ${ }^{4}$ and be replaced in the same quality and quantity by new vital bone. Ideally, bone substitute biomaterial is eliminated slowly after implantation in the patient, ${ }^{5}$ but its biodegradation rate allows the mechanical strength of the graft to be maintained during healing, ${ }^{6}$ balancing the resorption rate of the biomaterial with the patient's ability to form new bone. ${ }^{7}$

Over the past two decades, clinical and scientific research has demonstrated that the utilization of anorganic bovine bone $(\mathrm{ABB})$ as grafting material can 
produce very high clinical success rates. ${ }^{8} \mathrm{ABB}$ is a deproteinized, sterilized, bovine cancellous bone that provides a scaffold and a matrix for bone cell migration and is integrated into the natural physiologic remodeling process; it is frequently utilized as a bone substitute when insufficient autogenous cortical bone (ACB) is available for the graft. ${ }^{9}$

Knowledge of the resorption of available biomaterials is important for the clinician in order to obtain a satisfactory clinical outcome. ${ }^{10}$ The resorption of $\mathrm{ABB}$ remains controversial, and results have varied according to the model used (human ${ }^{11,12}$ or animal ${ }^{13,14}$ ), the cell type investigated (e.g., giant cells ${ }^{15}$ or osteoclasts ${ }^{10,16}$ ), the pathological technique, ${ }^{17}$ or the histological preparation method. ${ }^{18}$

Osteoclasts develop on bone surfaces, whereas other multinucleated cells, such as giant cells, primarily differentiate at chronic inflammatory sites in response to bacterial invasion or foreign bodies. ${ }^{19}$ A foreign body reaction can be caused by a xenograft that is clinically nonimmunogenic, nontoxic, and chemically inert, ${ }^{15}$ which can impair hard tissue deposition ${ }^{20}$ and modify its osteoconductive properties. A better understanding of the osteoclastic degradation of bone substitute materials is of interest because osteoclastic resorption may affect bone formation during the coupled activity of bone cells in the remodeling process. ${ }^{21}$ It is documented that multinucleated cells originate from mononuclear phagocytes that belong to the hematopoietic line of stem cells. $^{22}$ The biological processes that differentiate the final cellular type from monocytes or macrophages may be conditioned by local stimuli such as growth factors or cytokines. Hence, different responses may be expected according to the biological milieu of the biomaterial site.

The objective of this study was to examine the behavior of ABB in maxillary sinus grafts at 6 months, 3 years, and 7 years after healing, analyzing the types of degrading cells related to $\mathrm{ABB}$ particles, determining $\mathrm{ABB}$ resorption in core biopsies from humans after sinus augmentation with a composite graft composed of $\mathrm{ABB}$ and $\mathrm{ACB}$ (1:1 ratio), and studying its relationship with morphological and morphometric variables.

\section{MATERIALS AND METHODS}

\section{Study Design}

Patients in need of sinus augmentation were recruited for this prospective study at the University of Granada
(Spain), which was conducted in accordance with the Helsinki declaration ${ }^{23}$ and approved by the ethical committee of the university for studies involving human subjects. Informed consent to study participation was obtained from patients during the screening phase. Information on their medical and dental history was gathered by means of a questionnaire. Inclusion criteria were the following: age between 18 and 85 years, physical status of I or II according to the American Society of Anesthesiologists, absence of uncontrolled systemic disease or condition known to alter bone metabolism (e.g., osteoporosis, diabetes mellitus, etc.), adequate oral hygiene (O'Leary plaque score $\leq 20 \%$ ), and $<5$-mm remaining bone height by radiographic measurement on panoramic film. ${ }^{24}$ Exclusion criteria were the following: receipt of antibiotics in previous 3 months, longterm use ( $>6$ months) of medications known to modify bone metabolism (e.g., bisphosphonates, corticosteroids, etc.), pregnancy or intention to become pregnant, the presence of sinus conditions or sepsis, and a history of cancer and/or irradiation in the oral cavity.

Seventeen grafting procedures were conducted using a previously reported surgical and restorative procedure. ${ }^{25}$ Patients underwent a delayed implant approach of between 6 months, although some of them required implant placement after periods of 3 years and even 7 years. A trephine $(3 \mathrm{~mm}$ internal diameter, $4 \mathrm{~mm}$ external diameter) was used to collect bone core biopsies after a 6-month healing period in 10 cases, after a delay of 3 years in four cases, and after a delay of 7 years in three cases. The number of patients in this study is limited because of the singularity to take bone cores from patients after 3 or 7 years after grafting, due to ethical reasons. Especial circumstances are needed to involve these patients in this study, such as failed implants in the surrounding area, patients that moved to a different area to live and left their treatments without placing the fixations, or illness (different from the exclusion criteria) that did not allow the patients to attend to their normal appointments.

\section{Radiographic Variables}

Standardized digital panoramic films (Kodak ACR2000, Eastman Kodak Company, Rochester, NY, USA) were obtained for each patient before and immediately after the sinus graft surgery, before the implant insertion, and at prosthesis delivery. A single examiner used specific software (Digident Dent-A-View, Version 1.0, 
DigiDent, DIT, Nesher, Israel) to measure the total bone height at the point of shortest remaining alveolar bone before the surgery and the maximum vertical augmentation after grafting and at implant placement.

Histological Study. Harvested biopsies were immediately placed in $10 \%$ buffered formalin for 24 hours, then decalcified in a solution containing formaldehyde $(10 \%$ $\mathrm{w} / \mathrm{v})$, formic acid $(8 \% \mathrm{w} / \mathrm{v})$, and methanol $(1 \% \mathrm{w} / \mathrm{v})$ for $\geq 20$ days (Decalcifier I, Surgipath ${ }^{\circledR}$ Europe Ltd, Peterborough, UK), and subsequently embedded in paraffin. Samples were dewaxed and hydrated, and $4-\mu \mathrm{m}$ sections were cut along the central axis of the biopsies. Sections were processed for hematoxylin-eosin, periodic acid Schiff, and Masson's trichrome staining. A millimeter scale in the eyepiece of a $\mathrm{BH} 2$ microscope (Olympus Optical Company, Ltd, Tokyo, Japan) was used (at $\times 40$ magnification) to count osteoblasts, osteoclasts, and osteocytes per square millimeter. Results were expressed as number of positive cells per square millimeter. Bone histomorphometric analysis was semiautomatically performed on Masson trichrome-stained sections by assessing 10 random digital images per sample, obtained with a microscope ( $\times 10$ magnification) equipped with digital camera (DP70, Olympus). Images were transferred to a computer and analyzed using specialized software (Image J, NIH, Scion Corporation, Frederick, MD, USA, http://rsb.info.nih.gov/ij/). Vital bone, remaining $\mathrm{ABB}$ particles, and nonmineralized tissue percentages were separately quantified. Results were expressed as percentages. Bone formation was estimated by recording the number of osteoid lines in the total core length.

Immunohistochemistry Analysis. Decalcified and paraffin-embedded sections were dewaxed, hydrated, and heat treated in $1 \mathrm{mM}$ ethylene-diamine-tetra-acetic acid (EDTA) buffer for antigenic unmasking. Sections were incubated for 30 minutes at room temperature with the following: prediluted tartrate resistant acid phosphatase (TRAP) (clone 26E5) and cathepsin K (polyclonal) to identify osteoclasts; cycloxygenase (COX-2) (clone SP21); CD68 (clone KP1) to identify monocytes/ macrophages; or vimentin (clone V9) to identify mesenchymal cells (as positive control). All antibodies were purchased from Master Diagnóstica (Granada, Spain). The immunohistochemical study was done with an automatic immunostainer (Autostainer 480, LabVision, Fremont, CA, USA) using the micropolymer-peroxidase- based method (Ultravision Quanto; Thermo Fisher Scientific, Kalamazoo, MI, USA), followed by development with diaminobenzidine (Master Diagnóstica). A millimeter scale in the eyepiece of a $\mathrm{BH} 2$ microscope (Olympus) with a $\times 40$ objective was used to count the number of positive cells per square millimeter.

Statistical Analysis. After descriptive analysis, the Kruskal-Wallis and Mann-Whitney $U$ test were used to evaluate the significance of differences, comparing clinical, morphological, and morphometric values. $p<.05$ was considered significant. SPSS-Windows 15.0 (SPSS Inc., Chicago, IL, USA) was used for the analyses.

\section{RESULTS}

The mean age of the patients was $46.29 \pm 8.10$ years, in a range between 35 and 63 years. Mean sinus elevation augmentation vertical resorption was $0.30 \pm 0.14 \mathrm{~mm}$, with no statistically significant differences among the three study groups (Table 1).

\section{Histological and Histomorphometric Results}

After 6 months, 3 years, and 7 years, ABB particles remained detectable on trabecular bone in a slightly lower proportion than in the original graft (Figure 1). A normal woven and lamellar pattern of trabecular bone had formed throughout the graft in all patients receiving ABB plus ACB (1:1) grafts, and biopsies from the augmentation area showed this trabecular bone in different proportions. Image analysis revealed similar mean values for vital bone, nonmineralized connective tissue, and remnant $\mathrm{ABB}$ particles at all three measurement time points (see Table 1).

In all histological samples, multinuclear cells were attached to the surface of ABB particles and had the same shape and size as osteoclasts adhering to bone tissue. Most of these cells showed osteoclastic features, including polarization, ruffled border, and TRAP and cathepsin $\mathrm{K}$ activity (Figure 2). However, as detailed in Table 1, a significant decrease over time was observed (KruskalWallis test) in the osteoclast count (TRAP positive, $p=.014$; cathepsin $\mathrm{K}$ positive, $p=.021$ ) and number of osteoid lines ( $p=.038$ ), whereas osteocyte and osteoblast counts remained similar at all measurement time points.

The presence of canals, resorptive trails, and vessels within $\mathrm{ABB}$ particles was observed in $45 \%$ of biopsies at 6 months and in $100 \%$ of those at 3 and 7 years $(p<.047$, Kruskal-Wallis test). In the majority of cases 


\begin{tabular}{|c|c|c|c|c|}
\hline Variables & 6 Months $(n=10)$ & 3 Years $(n=4)$ & 7 Years $(n=3)$ & $p$ Values* \\
\hline Age & $47.2 \pm 17.4$ & $45.7 \pm 11.8$ & $44.0 \pm 7.2$ & .706 \\
\hline Graft resorption & $0.34 \pm 0.19$ & $0.25 \pm 0.10$ & $0.29 \pm 0.12$ & .694 \\
\hline Bone $(\%)$ & $36.77 \pm 23.64$ & $32.45 \pm 10.07$ & $39.170 \pm 11.58$ & .170 \\
\hline ABB (\%) & $21.64 \pm 19.60$ & $20.25 \pm 10.44$ & $11.58 \pm 21.81$ & .551 \\
\hline CT (\%) & $41.58 \pm 16.41$ & $47.29 \pm 8.9$ & $49.23 \pm 6.01$ & .164 \\
\hline Osteocytes $/ \mathrm{mm}^{2}$ & $783.55 \pm 545.67$ & $838.71 \pm 645.77$ & $574.19 \pm 212.90$ & .191 \\
\hline Osteoblasts $/ \mathrm{mm}^{2}$ & $152.11 \pm 115.39$ & $346.77 \pm 315.09$ & $80.64 \pm 58.15$ & .226 \\
\hline Osteoclasts $/ \mathrm{mm}^{2}$ & $215.26 \pm 70.13$ & $99.19 \pm 44.23$ & $40.10 \pm 29.70$ & .050 \\
\hline Osteoid lines & $13.7 \pm 8.1$ & $7.25 \pm 5.83$ & $3.0 \pm 1.0$ & .038 \\
\hline $\mathrm{CD} 68 / \mathrm{mm}^{2}$ & $28.69 \pm 25.68$ & $65.42 \pm 34.32$ & $31.18 \pm 27.05$ & .167 \\
\hline $\mathrm{TRAP} / \mathrm{mm}^{2}$ & $242.17 \pm 66.18$ & $42.22 \pm 30.26$ & $34.15 \pm 42.90$ & .014 \\
\hline Cathepsin $\mathrm{K} / \mathrm{mm}^{2}$ & $200.75 \pm 42.09$ & $35.36 \pm 28.15$ & $24.21 \pm 19.45$ & .021 \\
\hline
\end{tabular}

Values are expressed as mean \pm standard deviation.

${ }^{\star}$ Kruskal-Wallis test.

$p$ Values with statistical significance are in bold.

$\mathrm{ABB}=$ anorganic bovine bone; $\mathrm{CT}=$ connective tissue; $\mathrm{TRAP}=$ tartrate resistant acid phosphatase.
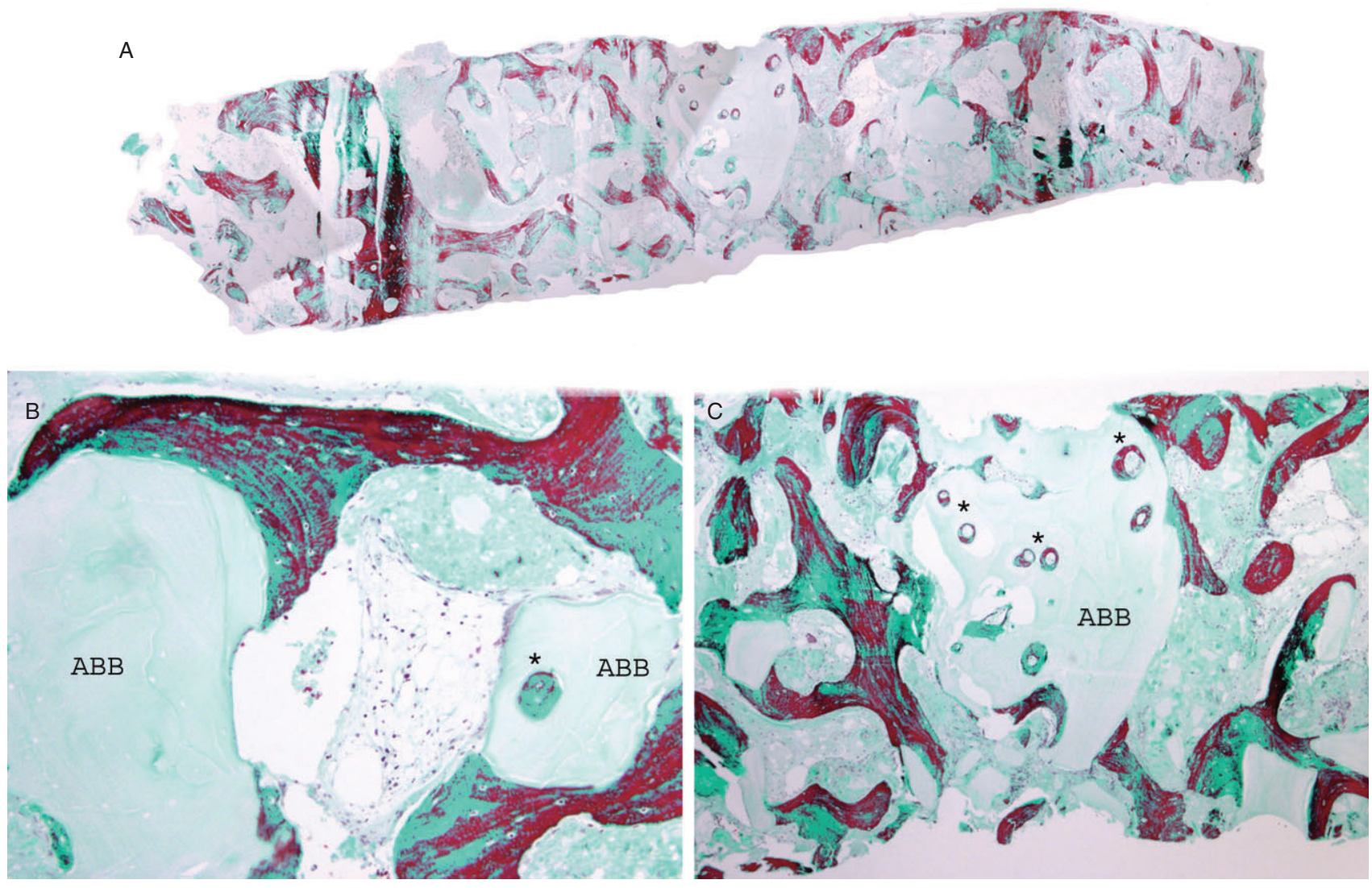

Figure 1 (A) Panoramic image of bone core biopsy taken after 7 years from maxillary sinus augmentation. Note the persistence of anorganic bovine bone $(\mathrm{ABB})$ particles (Masson trichrome, original magnification $\times 2$ ). Presence of canals, resorptive trails, and vessels within $\mathrm{ABB}$ particles at 3 years (B) and 7 years (C) (asterisk) (Masson trichrome, original magnification $\times 20$ ). 


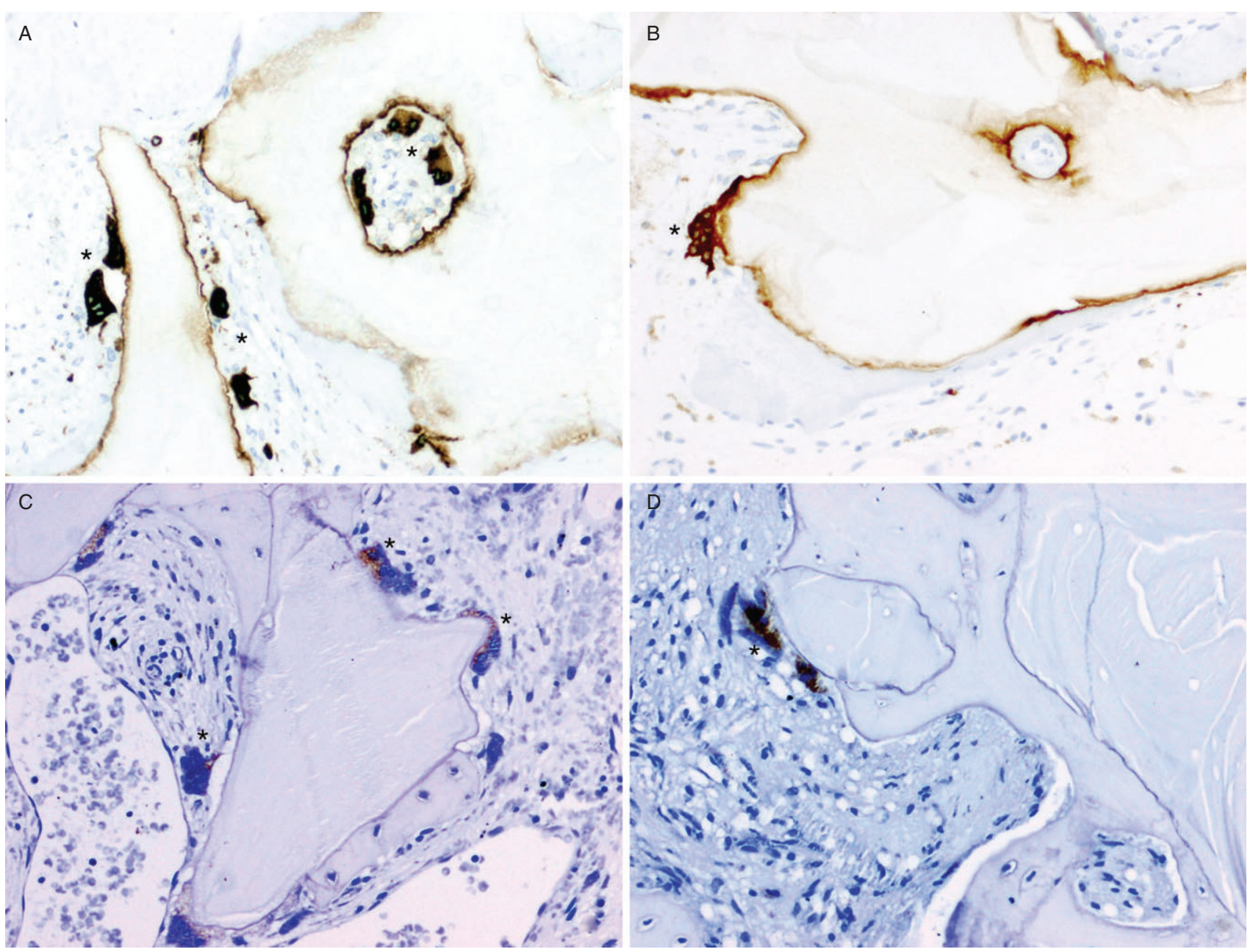

Figure 2 Osteoclast cell tartrate resistant acid phosphatase positive (asterisk) in maxillary sinus augmentation biopsies at 6 months (A) and at 7 years (B) attached to the surface of anorganic bovine bone particles. Osteoclast cell cathepsin K positive (asterisk) at 6 months (C) and at 7 years (D). Note the significant decrease in the osteoclast count (polymer-peroxidase-based method, original magnification $\times 20)$.

with the presence of Haversian and Volkmann's canals, ABB particles were recolonized by vessels through preexisting canals (see Figure 1).

\section{DISCUSSION}

The biodegradation of $\mathrm{ABB}$ is controversial. Some authors found that $\mathrm{ABB}$ was resorbed in the host tissue ${ }^{26,27}$ but others reported that it was not. ${ }^{28,29}$ This discrepancy may be attributable to differences in the type of study (animal vs human studies), surgical approach, biopsy technique, or histological evaluation method. ${ }^{18}$ In our samples, the significant decrease in osteoclast count suggests a true reduction in biodegradation.

Wallace and colleagues followed the sequential healing process of a sinus graft in a patient and detected no signs of deproteinized bovine bone particles at 20 months of healing, ${ }^{30}$ but it is not clear whether this finding reflected the biopsy technique used or was truly the result of resorption. Other authors ${ }^{31}$ reported a higher final amount of vital bone with greater amounts of $\mathrm{ABB}$ in the graft $(37.7 \pm 31.3 \%$ with $100 \% \mathrm{ACB}$ vs $39.9 \pm 8 \%$ with $20 \%$ ACB: $80 \%$ ABB vs $41.7 \pm 26.6 \%$ with $100 \% \mathrm{ABB}$ ), and similar results were obtained by our group. ${ }^{25}$ This may imply greater resorption with the placement of more ABB because $41.7 \%$ of the space initially occupied by $100 \%$ ABB becomes new vital host bone. However, although the initial amounts of each biomaterial are known, it is not possible to evaluate resorption by this mechanism because its precise distribution within the defect is not known. One author claimed that, because the structure of Bio-Oss ${ }^{\circledR}$ (Geistlich Söhne AG, Wolhusen, Switzerland) is porous, 
ABB could only occupy 25 to $30 \%$ of the available space. ${ }^{17}$ For ethical reasons, biopsies are generally taken from humans by using a trephine drill, which means that the clinician has no precise knowledge of the original position of the biopsy (direction, inclination, depth, and buccopalatal distances) or the initial proportion of the biomaterial in the selected area.

The measurement of surface ABB particles may not be the most appropriate procedure to determine resorption. ABB (Bio-Oss) is obtained from two different bone types, cortical and cancellous bone, which have different resorption rates, and it is commercially available in two particle sizes $(0.25-1$ and $1-2 \mathrm{~mm}) .{ }^{9}$ The variability of particle size within the same sample is very high, and differences in resorption cannot be established if the initial pregraft size of particles is not known. Errors can also be introduced through histological procedures such as the decalcification of deproteinized bovine bone particles, which produces shrinkage that might be misinterpreted as resorption. ${ }^{18}$

The presence of cortical autogenous bone is an essential characteristic of our composite graft. Cobb and colleagues compared the use of nonresorbable and lowgrade resorption bone substitutes and concluded that a mixture of equal volumes of nonresorbable and autogenous bone was optimal for grafting. ${ }^{32}$ For the clinical augmentation of a severely resorbed posterior maxilla, a mixture of $50 \% \mathrm{ABB}$ and $50 \%$ autogenous bone was found to ensure the primary stability of dental implants after a 6-month healing period. ${ }^{9}$ The advantage of autogenous bone as a graft material is the rapid angiogenic growth of vessels from the surrounding host bone. This may help to vascularize parts of the graft and its cells, which would subsequently participate in local metabolism, leading to osteoclastic resorption and functionally oriented osteoblastic remodeling. Resorption of the autogenous bone includes the release of growth factors involved in the formation of new capillary sprouts (e.g., platelet-derived growth factor and transforming growth factor beta), the proliferation of stem cells, and the activation of macrophages. ${ }^{33}$ Grafted autogenous bone particles appear to act as local bone growth centers throughout the graft area $^{34}$ and to provide osteoclasts and their progenitors, which may influence the remodeling of the total mineralized mass. ${ }^{9}$ However, the osteoclasts detected in our histological preparations are unlikely to have derived from the original autologous graft because these cores were obtained after at least 6 months of healing, and Tadjoedin and colleagues found that all original graft bone was remodeled after 5 months. ${ }^{9}$

If resorption occurs, it is important to establish the types of cell that promote this event and surround the ABB particles. Studies of biopsies harvested in humans after 3 years found $\mathrm{ABB}$ particles to be in close contact with giant cells but without exhibiting signs of resorption. ${ }^{27}$ Hallman and Thor interpreted lacunae on the surfaces of deproteinized bovine bone particles as lacunae present in the original donor material rather than signs of possible resorption. They argued that deproteinized bovine bone may be a nonresorbable grafting material in humans ${ }^{18}$ and, even though giant cells may be in the vicinity of $\mathrm{ABB}$ particles, osteoclastic cells are unlikely to resorb or degrade bovine bone that has been deproteinized. However, Tadjoedin and colleagues described the presence of numerous TRAPpositive multinucleated cells in contact with $\mathrm{ABB}$ granules, often localized in shallow resorption lacunae, similarly what happens in some of our samples, suggesting that $\mathrm{ABB}$ granules were gradually degraded and resorbed by the activity of osteoclasts. ${ }^{9}$ This is a frequent finding in our samples, in which TRAP-positive multinucleated cells were consistently found both on the ABB particles and within them (e.g., on canals), promoting their central resorbability (see Figure 2). Furthermore, our group previously demonstrated a considerably higher amount of osteoclasts in the grafted area than in the pristine maxillary bone. ${ }^{35}$

Numerous researchers have reported multinucleated cells on the surface of ABB material, ${ }^{16,36,37}$ but it remains to be elucidated whether they are active osteoclasts, ${ }^{16}$ nonactive/impaired osteoclasts, ${ }^{38}$ giant cells,,${ }^{15,27}$ or macrophages/monocytes undergoing fusion. ${ }^{22}$ The clinical response may be influenced by the type of cells presented, which is therefore a highly relevant issue. Thus, giant cells differentiate in chronic inflammatory sites in response to bacterial invasion and foreign bodies, ${ }^{19}$ whereas the presence of osteoclasts may represent normal bone tissue remodeling.

Some animal studies reported on the early phases of healing, which are associated with inflammatory processes $^{20}$ that can alter normal hard tissue deposition, and multinucleated cells found on the xenograft surface during these phases may be giant cells. Araújo and colleagues proposed that neutrophilic leukocytes (polymorphonuclear cells) migrate to the surface of foreign 
particles during the first phase of healing and are replaced with multinuclear TRAP-positive cells (osteoclasts) during a second phase. These osteoclasts remove material from the xenogeneic graft surface but disappear from the ABB granules after 1 to 2 weeks, when they are followed by osteoblasts that lay down bone mineral in the collagen bundles of the provisional matrix. ${ }^{16}$ This phenomenon may explain the significant positive relationship in our samples between COX-2 expression in multinucleated cells and greater bone formation $\left(r_{s}\right.$ : $0.729, p=.04$, Spearman test). Osteoblastic bone formation is usually associated with osteoclastic bone resorption ${ }^{39}$ in the remodeling process. ${ }^{10}$ However, according to Araújo and colleagues ${ }^{40}$ no multinucleated cells can be expected on the ABB surface after 3 months because they undergo apoptosis and disappear after completing their function. This contrasts with our clinical findings of different multinucleated cells (CD68 positive) and osteoclasts (TRAP and cathepsin K positive) after 6 months of healing, with no case of inflammatory response being observed in our samples. It is reasonable to assume that different cellular events are taking place at 6 months and that different stages of differentiation of these resorptive cells may coexist. Given that bone tissue is under continuous remodeling, osteoclasts must be present in the samples at this time (6 months), but tissue remodeling behavior may vary over time. In the experimental study by Araújo and colleagues, multinucleated cells on the graft surface were almost never found in resorption bays in tissue samples from grafted sites, whereas morphologically similar cells present on adjacent surfaces of host bone were almost consistently located in characteristic Howship's lacunae and were classified as active osteoclasts. ${ }^{15}$ The biological behavior was different in our samples; after 6 months of healing, osteoclasts were usually active on $\mathrm{ABB}$ particles, promoting bone remodeling units, but they were rarely active on new vital bone.

Osteoclast attachment and resorptive activity involves the formation of cellular attachments to proteins in the normal bone matrix ${ }^{41}$ or to proteins adsorbed on the biomaterial surface. ${ }^{12}$ The present biomaterial is anorganic and therefore expected to contain no proteins, ${ }^{18}$ compromising the biological effects of osteoclasts, ${ }^{38}$ but some proteins were detectable on the $A B B$ particles in our samples. The distribution of TRAP in our samples was of particular interest, being expressed solely on the graft particles and never on vital bone, indicating a selective resorption of the xenogeneic material (see Figure 2). An identical expression pattern was found for osteopontin (data not shown), which not only activates osteoclasts for bone matrix resorption ${ }^{42}$ but can also induce osteoclast migration in an $\alpha_{v} \beta_{3}$ integrin-dependent manner. ${ }^{43}$ In support of this proposition, osteoclast migration was found to be mediated by phosphorylated osteopontin and regulated by the endogenous TRAP. ${ }^{44}$

The significant decrease in the osteoclast count over time in our series could suggest that the main cause of $\mathrm{ABB}$ persistence is a reduction in remodeling activity.

\section{CONCLUSION}

Resorption of ABB material was observed in bone cores from humans, with evidences of diverse active multinucleated cells on this biomaterial. The present finding of a decrease in osteoclast count over time would explain the long-term persistence of $\mathrm{ABB}$ observed. Further studies with more cases and different graft maturation times are required to elucidate the resorption rates and cell events underlying these phenomena.

\section{ACKNOWLEDGMENTS}

The authors are grateful to María Dolores Rodríguez and Jorge A. Payá for technical assistance.

\section{CONFLICT OF INTEREST AND SOURCE OF FUNDING}

This investigation was supported in part by Research Groups \#CTS-138 and \#CTS-583 (Junta de Andalucía, Spain).

The authors declare that they have no conflict of interests. Some of the results of this paper were presented at the First National Congress of the Spanish College of Oral Implantologists in 2011.

\section{REFERENCES}

1. Kanczler JM, Oreffo RO. Osteogenesis and angiogenesis: the potential for engineering bone. Eur Cell Mater 2008; 15:100 114.

2. Watzek G, Fürst G, Gruber R. Biologic basis of sinus grafting. In: Jensen OT, ed. The sinus bone graft. Barcelona, Spain: Quintessence Books, 2006:13-26.

3. Götz W, Gerber T, Michel B, Lossdörfer S, Henkel KO, Heinemann F. Immunohistochemical characterization of nanocrystalline hydroxyapatite silica gel (NanoBone(r)) osteogenesis: a study on biopsies from human jaws. Clin Oral Implants Res 2008; 19:1016-1026. 
4. Radomsky ML, Thompson AY, Spiro RC, Poser JW. Potential role of fibroblast growth factor in enhancement of fracture healing. Clin Orthop Relat Res 1998; 355 Suppl:S283S293.

5. Giannoudis PV, Dinopoulos H, Tsiridis E. Bone substitutes: an update. Injury 2005; 36(Suppl 3):S20-S27.

6. Chaikof EL, Matthew H, Kohn J, Mikos AG, Prestwich GD, Yip CM. Biomaterials and scaffolds in reparative medicine. Ann N Y Acad Sci 2002; 961:96-105.

7. Schilling AF, Linhart W, Filke S, et al. Resorbability of bone substitute biomaterials by human osteoclasts. Biomaterials 2004; 25:3963-3972.

8. Aghaloo TL, Moy PK. Which hard tissue augmentation techniques are the most successful in furnishing bony support for implant placement? Int J Oral Maxillofac Implants 2007; 22(Suppl):49-70.

9. Tadjoedin ES, de Lange GL, Bronckers AL, Lyaruu DM, Burger EH. Deproteinized cancellous bovine bone (Bio-Oss) as bone substitute for sinus floor elevation. A retrospective, histomorphometrical study of five cases. J Clin Periodontol 2003; 30:261-270.

10. Perrotti V, Nicholls BM, Horton MA, Piattelli A. Human osteoclast formation and activity on a xenogenous bone mineral. J Biomed Mater Res A 2009; 90:238-246.

11. Piattelli M, Favero G, Scarano A, Orsini G, Piattelli A. Bone reactions to anorganic bovine bone (Bio-Oss) used in sinus augmentation procedures: a histologic long-term report of 20 cases in humans. Int J Oral Maxillofac Implants 1999; 14:835-840.

12. Galindo-Moreno P, Avila G, Fernández-Barbero JE, et al. Evaluation of sinus floor elevation using a composite bone graft mixture. Clin Oral Implants Res 2007; 18:376382.

13. McAllister BS, Margolin MD, Cogan AG, Buck D, Hollinger JO, Lynch SE. Eighteen-month radiographic and histologic evaluation of sinus grafting with anorganic bovine bone in the chimpanzee. Int J Oral Maxillofac Implants 1999; 14:361-368.

14. Carmagnola D, Berglundh T, Lindhe J. The effect of a fibrin glue on the integration of Bio-Oss with bone tissue. A experimental study in labrador dogs. J Clin Periodontol 2002; 29:377-383.

15. Araújo M, Linder E, Lindhe J. Effect of a xenograft on early bone formation in extraction sockets: an experimental study in dog. Clin Oral Implants Res 2009; 20:1-6.

16. Araújo MG, Liljenberg B, Lindhe J. Dynamics of Bio-Oss Collagen incorporation in fresh extraction wounds: an experimental study in the dog. Clin Oral Implants Res 2010; 21:55-64.

17. Peetz M. Characterization of xenogenic bone material. In: Boyne PJ, ed. Osseous reconstruction of the maxilla and the mandible - surgical techniques using titanium mesh and bone mineral. Berlin: Quintessence, 1997:87-100.
18. Hallman M, Thor A. Bone substitutes and growth factors as an alternative/complement to autogenous bone for grafting in implant dentistry. Periodontol 2000 2008; 47:172-192.

19. Vignery A. Osteoclasts and giant cells: macrophagemacrophage fusion mechanism. Int J Exp Pathol 2000; 81:291-304.

20. Luttikhuizen DT, Harmsen MC, Van Luyn MJA. Cellular and molecular dynamics in the foreign body reaction. Tissue Eng 2006; 12:1955-1970.

21. Perrotti V, Nicholls BM, Piattelli A. Human osteoclast formation and activity on an equine spongy bone substitute. Clin Oral Implants Res 2009; 20:17-23.

22. Bredan BF, Xing L. Biology of RANK, RANKL, and osteoprotegerin. Arthritis Res Ther 2007; 9:1-7.

23. Schuklenk U, Ashcroft R. International research ethics. Bioethics 2000; 14:158-172.

24. Wang HL, Katranji A. ABC sinus augmentation classification. Int J Periodontics Restorative Dent 2008; 28:383-389.

25. Galindo-Moreno P, Moreno-Riestra I, Avila G, et al. Effect of anorganic bovine bone to autogenous cortical bone ratio upon bone remodeling patterns following maxillary sinus augmentation. Clin Oral Implants Res 2011; 22:857-864.

26. Yildirim M, Spiekermann H, Biesterfeld S, Edelhoff D. Maxillary sinus augmentation using xenogenic bone substitute material Bio-Oss in combination with venous blood. A histologic and histomorphometric study in humans. Clin Oral Implants Res 2000; 11:217-229.

27. Hallman M, Lundgren S, Sennerby L. Histologic analysis of clinical biopsies taken 6 months and 3 years after maxillary sinus floor augmentation with $80 \%$ bovine hydroxyapatite and $20 \%$ autogenous bone mixed with fibrin glue. Clin Implant Dent Relat Res 2001; 3:87-96.

28. Valentini P, Abensur D, Densari D, Graziani JN, Hammerle C. Histological evaluation of Bio-Oss in a 2-stage sinus floor elevation and implantation procedure. A human case report. Clin Oral Implants Res 1998; 9:59-64.

29. Schlegel AK, Donath K. Bio-Oss - a resorbable bone substitute? J Long Term Eff Med Implants 1998; 8:201209.

30. Wallace SS, Froum SJ, Tarnow DP. Histologic evaluation of a sinus elevation procedure: a clinical report. Int J Periodontics Restorative Dent 1996; 16:46-51.

31. Hallman M, Sennerby L, Lundgren S. A clinical and histologic evaluation of implant integration in the posterior maxilla after sinus floor augmentation with autogenous bone, bovine hydroxyapatite, or a 20:80 mixture. Int J Oral Maxillofac Implants 2002; 17:635-643.

32. Cobb CM, Eick JD, Barker BF, Mosby EL, Hiatt WR. Restoration of mandibular continuity defects using combinations of hydroxylapatite and autogenous bone: microscopic observations. J Oral Maxillofac Surg 1990; 48:268-275.

33. Schlegel KA, Fichtner G, Schultze-Mosgau S, Wiltfang J. Histologic findings in sinus augmentation with autogenous 
bone chips versus a bovine bone substitute. Int J Oral Maxillofac Implants 2003; 18:53-58.

34. Joldersma M, Klein-Nulend J, Oleksik AM, Heyligers IC, Burger EH. Estrogen enhances mechanical stress-induced prostaglandin production by bone cells from elderly women. Am J Physiol Endocrinol Metab 2001; 280:E436-E442.

35. Galindo-Moreno P, Moreno-Riestra I, Avila G, et al. Histomorphometric comparison of maxillary pristine bone and composite bone graft biopsies obtained after sinus augmentation. Clin Oral Implants Res 2010; 21:122-128.

36. Merkx MA, Maltha JC, Freihofer HP. Incorporation of composite bone implants in the facial skeleton. Clin Oral Implants Res 2000; 11:422-429.

37. Simion M, Fontana F, Rasperini G, Maiorana C. Vertical ridge augmentation by expanded-polytetrafluoroethylene membrane and a combination of intraoral autogenous bone graft and deproteinized anorganic bovine bone (Bio Oss). Clin Oral Implants Res 2007; 18:620-629.

38. Taylor JC, Cuff SE, Leger JPL, Morra A, Anderson GI. In vitro osteoclast resorption of bone substitute biomaterials used for implant site augmentation: a pilot study. Int J Oral Maxillofac Implants 2002; 17:321-330.
39. Yamada S, Heymann D, Bouler JM, Daculsi G. Osteoclastic resorption of calcium phosphate ceramics with different hydroxyapatite/ $\beta$-tricalcium phosphate ratios. Biomaterials 1997; 18:1037-1041.

40. Araújo M, Linder H, Wennström J, Lindhe J. The influence of Bio-Oss ${ }^{\circledR}$ collagen on healing of an extraction socket: an experimental study in the dog. Int J Periodontics Restorative Dent 2008; 28:123-135.

41. Katayama Y, House CM, Udagawa N, et al. Casein kinase 2 phosphorylation of recombinant rat osteopontin enhances adhesion of osteoclasts but not osteoblasts. J Cell Physiol 1998; 176:179-187.

42. Duong LT, Rodan GA. The role of integrins in osteoclast function. J Bone Miner Metab 1999; 17:1-6.

43. Chellaiah MA, Hruska KA. The integrin alpha(v)beta(3) and CD44 regulate the actions of osteopontin on osteoclast motility. Calcif Tissue Int 2003; 72:197-205.

44. Ek-Rylander B, Andersson G. Osteoclast migration on phosphorylated osteopontin is regulated by endogenous tartrateresistant acid phosphatase. Exp Cell Res 2010; 316:443-451. 